\title{
Dietary and socio-economic factors associated with obesity among Kuwaiti college men
}

\author{
Abdulwahab Naser Al-Isa* \\ Department of Community Medicine and Behavioural Sciences, Faculty of Medicine, University of Kuwait, \\ PO Box 24923, Safat, Code 13110, Kuwait
}

(Received 20 August 1998 - Revised 25 March 1999 - Accepted 23 April 1999)

\begin{abstract}
Obesity has been on the increase among people of the Arabian Gulf countries. Overweight and obesity among 18-29-year-old Kuwaiti men increased by 23.4 and $14.8 \%$ respectively, between 1980 and 1993. The objective of the present study was to explore factors associated with overweight and obesity in a sample of 515 Kuwaiti college men studied in 1997. Weight and height were measured. The index of adiposity used was the BMI, which is the weight (kg) divided by the height $(\mathrm{m})$ squared $\left(\mathrm{kg} / \mathrm{m}^{2}\right)$. The men were classified as overweight $\left(\mathrm{BMI}>25 \mathrm{~kg} / \mathrm{m}^{2}\right)$ or obese (BMI $>30 \mathrm{~kg} / \mathrm{m}^{2}$ ). The associated factors obtained through questionnaires included age, marital status, governorate, number of siblings, suffering from a chronic disease, subjects' parental obesity, education and occupation, number of major meals eaten, eating between meals, family income, number of servants, number of people living at home, exercising, last dental and physical check-up, dieting, year of study, highest desired degree after college, countries preferred for visiting, and socio-economic status. The results of the study revealed that 38.5 and $11.1 \%$ of the students were overweight and obese respectively. Factors that were found to be significantly associated with overweight and obesity among the men included age, marital status, last dental check-up, exercising, subjects' parental obesity, dieting and year of study. Logistic regression analysis of significant associated factors revealed that the same factors contributed to the development of overweight and obesity.
\end{abstract}

\section{Obesity: Body mass index: Kuwait}

Obesity is a risk factor for development of a variety of diseases, chief among which are diabetes, hypertension, some forms of cancer and cardiovascular diseases (World Health Organization, 1990). These diseases are prevalent in Kuwait (Ministry of Public Health, 1996). The levels of overweight and obesity among young men in Kuwait are often lower than those among young women (Al-Isa, 1995). Differences between men and women in the prevalence of overweight and obesity have also been observed in other countries (Bellisle et al. 1995). The concern to lose weight to improve appearance is less prevalent among young males than among young females (Sciacca et al. 1991; Smith et al. 1998). However, there is a general concern among young people about weight during their formative years when changes in the body occur more rapidly than in the latter stages of life. College students' dietary habits have been criticized for their nutritional inadequacies and faddism. Students face the risk of overweight and obesity because of the dynamic changes in their levels of physical activity and energy intake (Anonymous, 1997; Haberman \& Luffey, 1998; Makrides et al. 1998; Smith et al. 1998).
Obesity has been on the increase among people of the Arabian Gulf countries (Musaiger, 1990; Al-Isa, 1997). Prevalence rates for overweight and obesity among 1829-year-old Kuwaiti men have been reported to be 44.3 and $17.2 \%$ respectively, increasing among the $20-29$-year-olds to 67.7 and $32 \%$ respectively (Al-Isa, 1997). These percentages are higher than those reported in European countries, where prevalence rates for overweight and obesity among college students have been reported to be 8 and $1 \%$ respectively (Bellisle et al. 1995). Some studies have explored the association of various factors with overweight and obesity among people in the Arabian Gulf countries. These factors include age, sex, marital status, afternoon napping, availability of domestic help, employment, area of residence, family size and income, profession, eating between meals, and number of meals eaten per day (Kamel \& Martinez, 1984; Matter et al. 1990; Musaiger \& Al-Ansari, 1991-2; Musaiger et al. 1993; Musaiger \& Radwan, 1995; Al-Mannai et al. 1996; Amine \& Samy, 1996). It has been recommended that preventive measures for controlling the prevalence of obesity should be instituted 
during the early stages of life (World Health Organization, 1990). A study to explore factors associated with overweight and obesity among Kuwaiti college men has not been carried out in Kuwait. The purpose of the present study was to explore factors associated with overweight and obesity among college men attending Kuwait University.

\section{Methods \\ Sample}

Kuwait has one university attended by about 18000 students at the time of the study in 1997 (Registrar's Office, 1997, personal communication) and serving the five governorates (regions) of Kuwait: (1) the Capital and (2) Hawalli, which are entirely urban; (3) Farwaniya, which is mostly urban; (4) Ahmadi, which is about half rural; and (5) Jahra, which is mostly rural. All university male students registering in the first $5 \mathrm{~d}$ of registration for the 1997 spring semester were included in this study. These male students came from various socio-economic backgrounds in the five governorates (regions) of Kuwait which included both urban and rural areas. The total number of males studied was 515 out of 4200 students. The students were assembled in a side room and interviewed by trained male volunteer students; they had their weight and height measured by a nurse and completed a questionnaire which contained information on their socio-economic backgrounds. The refusal rate was less than $15 \%$ of the those coming in to register.

\section{Measurements}

Height was measured without shoes to the nearest $5 \mathrm{~mm}$. Weight was measured to the nearest $0.1 \mathrm{~kg}$ with the subject in light indoor clothes, with emptied pockets and without shoes using a precalibrated SECA scale (SECA Ltd, Birmingham, UK). The index of adiposity was the BMI, which is the weight $(\mathrm{kg})$ divided by the height $(\mathrm{m})$ squared $\left(\mathrm{kg} / \mathrm{m}^{2}\right)$. The classification (World Health Organization, 1990) of the BMI categories was as follows: non-obese (BMI $\leq 25 \mathrm{~kg} / \mathrm{m}^{2}$ ), overweight (BMI $>25 \mathrm{~kg} / \mathrm{m}^{2}$ ) and obese (BMI $>30 \mathrm{~kg} /$ $\mathrm{m}^{2}$ ). The socio-economic status score was based on parents' education and occupation (low, medium, high), family income, area of residence and number of servants, giving 1 for low, 2 for medium and 3 for high. An socio-economic status score was calculated for each student and scores ranged between 7 and 21. These were divided into three categories: low (7-11), medium (12-17), and high (18-21).

\section{Associated factors}

Age was divided into six categories: $\leq 18,19,20,21,22$ and $\geq 23$ years; marital status into two (single, married); governorate into five (Capital, Hawalli, Farwaniya, Ahmadi, Jahra); number of male, female and total siblings into four (none (0), low (1-3), medium (4-7), high ( $\geq 8)$ ); suffering from a chronic disease such as type 2 diabetes, CHD, hypertension, and dyslipidaemia into two (yes, no); obesity among parents into four (neither, father, mother, both); parents' education into three: low (illiterate or elementary), medium (intermediate or secondary), high (college or higher); parents' occupation into three: professional or semiprofessional, skilled or semi-skilled, and retired or not working; number of major meals eaten regularly into three $(1,2$, or 3 ); eating between meals into two (yes, no); family income per month into three (low $(<\$ 1500)$, medium $(\$ 1500$ $3000)$, high $(>\$ 3000)$ ); number of servants into three (none, 1-2 $\geq 3$ ); number of people residing at home into four (none (0), low (1-6), medium (7-10), high ( $\geq 11)$ ); exercising into two (yes, no); last dental or physical checkup into four (don't remember, more than 2 years ago, a year ago, last few months); dieting into two (yes, no); year of study into four (first, second, third, fourth); highest desired degree into two (college, higher); countries preferred for visiting into four (Western or Eastern countries, both, neither); and socio-economic status into three as described earlier.

\section{Rationale}

The rationale for including an analysis of number of siblings was to find out if family size contributed to the level of obesity. The inclusion of suffering from a chronic disease such as type 2 diabetes, CHD, hypertension or dyslipidaemia was to address the association between obesity and the aforementioned comorbidities. As for the number of servants, it was assumed that having domestic help would render the inhabitants of the household less physically active and hence more obese. Moreover, the ease by which food can be prepared and served with the availability of domestic help may encourage over-eating and hence may contribute to the level of obesity among the men. The number of people living at home was included to reflect the extended family situation; it was assumed that extended families eating in large groups would encourage overeating because Kuwaitis who live in the same house usually eat together. Last dental and physical check-ups were used as proxies for health awareness and preventive measures; it was assumed that people who pay close attention to their health are more likely to pay closer attention to their weight and to try to stay fit and keep weight in line. Year of study was used as an index of the level of apprehension or stress among the students as they progress in their studies; it was assumed that the level of apprehension or stress among the students regarding their success in college would change during their years of study. The level of apprehension or stress, it was further assumed, may promote over- or undereating among the men. Moreover, year of study was used to indicate if advancing years of study would present time constraints because of academic load on the level of physical activity among the students which would be reflected on their level of obesity.

The factor 'countries preferred for visiting' was used as a proxy or as an index for cosmopolitan $v$. traditional orientation; it was assumed that men who prefer visiting Western countries would be exposed to the Western model of acceptable physique which may be emulated by the men and sensitize them to adjust their weight. Moreover, the weather in such countries promotes outdoor physical and leisure activities which may affect their level of obesity and leave less time for sitting around in restaurants to eat. By contrast, those who visit Eastern (mainly Arabian) countries, would 
be exposed to the traditional Arab physique which usually tends toward plumpness; it was assumed that there may be a tendency among those visiting Arab countries for a greater consumption of food, often eaten in Arab (mostly Lebanese) or fast-food restaurants. Moreover, those who tend to visit Arabian countries tend also to wear the traditional attire, a loose robe which does not outline the structure of the body and may not provide as close a check on changes in weight as perhaps non-traditional attire, such as a suit, would. Highest desired degree was used as an indication of personal ambition and motivation; it was assumed that those who are more motivated and ambitious will pay closer attention to changes in their general appearance and, therefore, be more inclined to keep weight-related changes in check.

\section{Data analysis}

The SPSS (Statistical Package for Social Sciences, Windows version 7.5, 1997; SPSS Inc., Chicago, IL, USA) was used for data analysis. In addition to descriptive statistics, the $\chi^{2}$ test was used to assess the association between categorical variables. The logistic regression analysis was carried out using the binary variable: non-obese $\left(\mathrm{BMI} \leq 25 \mathrm{~kg} / \mathrm{m}^{2}\right.$ ) or overweight $\left(\geq 25 \mathrm{~kg} / \mathrm{m}^{2}\right) /$ obese $\left(\mathrm{BMI}>30 \mathrm{~kg} / \mathrm{m}^{2}\right)$ as a dependent variable and the other variables as independent variables. The logistic regression approach provides adjusted odd ratios (OR; estimated relative risk) attributed to the independent variables in relation to a reference group. A $P$ value of $\leq 0.05$ was used as the criterion of statistical significance.

\section{Results}

Table 1 shows the factors which were significantly associated with overweight (BMI $>25 \mathrm{~kg} / \mathrm{m}^{2}$ ) and obesity $\left(\right.$ BMI $>30 \mathrm{~kg} / \mathrm{m}^{2}$ ) among Kuwaiti college men. These factors included increased age $(P<0.001)$, marital status $(P<0.001)$, last dental check-up $(P<0.05)$, exercising $(P<0.05)$, subjects' parental obesity $(P<0 \cdot 01)$, dieting $(P<0.001)$, and increasing year of study $(P<0 \cdot 01)$.

Table 2 shows the risk of being overweight or obese among Kuwaiti college men with respect to increased age, marital status, last dental check-up, not exercising, subjects' parental obesity, dieting, and increasing year of study, using the logistic regression model, after adjusting for the confounding effects of other factors (OR with $95 \% \mathrm{CI}$ ).

The risk of overweight (BMI $>25 \mathrm{~kg} / \mathrm{m}^{2}$ ) among Kuwaiti college men increased with age, being significantly higher at 21 years of age $(P<0.01$, OR 3.79$)$ and $\geq 23$ years of age $(P<0.05$, OR 3.03$)$, in comparison with the youngest age group ( $\leq 18$ years). The risk of overweight was significantly $(P<0.05)$ higher (OR 2.31) among the married in comparison with single men. Men who reported having had a dental check-up 1 year ago had a significantly $(P<0 \cdot 01)$ lower risk

Table 1. Factors associated with overweight $\left(\mathrm{BMl}>25-30 \mathrm{~kg} / \mathrm{m}^{2}\right)$ and obesity $\left(\mathrm{BMl}>30 \mathrm{~kg} / \mathrm{m}^{2}\right.$ ) among Kuwaiti college men

\begin{tabular}{|c|c|c|c|c|c|c|c|}
\hline \multirow[b]{2}{*}{ Factor } & \multicolumn{2}{|c|}{ Non-obese } & \multicolumn{2}{|c|}{ Overweight } & \multicolumn{2}{|c|}{ Obese } & \multirow{2}{*}{$\begin{array}{l}P \text { value } \\
\left(\chi^{2} \text { test }\right)\end{array}$} \\
\hline & $n$ & $\%$ & $n$ & $\%$ & $n$ & $\%$ & \\
\hline Age (years) & & & & & & & $<0.001$ \\
\hline$\leq 18$ & 33 & $10 \cdot 4$ & 7 & $5 \cdot 0$ & 5 & $8 \cdot 8$ & \\
\hline 19 & 68 & $21 \cdot 5$ & 16 & $11 \cdot 3$ & 11 & $19 \cdot 3$ & \\
\hline 20 & 74 & $23 \cdot 3$ & 22 & $15 \cdot 6$ & 7 & $12 \cdot 3$ & \\
\hline 21 & 45 & $14 \cdot 2$ & 32 & $22 \cdot 7$ & 16 & $28 \cdot 0$ & \\
\hline 22 & 51 & $16 \cdot 1$ & 24 & $17 \cdot 0$ & 7 & $12 \cdot 3$ & \\
\hline$\geq 23$ & 46 & 14.5 & 40 & 28.4 & 11 & $19 \cdot 3$ & \\
\hline Marital status & & & & & & & $<0.001$ \\
\hline Single & 294 & $92 \cdot 7$ & 113 & $80 \cdot 1$ & 49 & $86 \cdot 0$ & \\
\hline Married & 23 & $7 \cdot 3$ & 28 & $19 \cdot 9$ & 8 & $14 \cdot 0$ & \\
\hline Last dental check-up & & & & & & & $<0.05$ \\
\hline Do not remember & 148 & $46 \cdot 7$ & 73 & $51 \cdot 8$ & 38 & $66 \cdot 7$ & \\
\hline$\geq 2$ years ago & 26 & 8.2 & 17 & $12 \cdot 1$ & 4 & $7 \cdot 0$ & \\
\hline A year ago & 59 & $18 \cdot 6$ & 16 & $11 \cdot 3$ & 6 & $10 \cdot 5$ & \\
\hline Last few months & 84 & $26 \cdot 5$ & 35 & 24.8 & 9 & $15 \cdot 8$ & \\
\hline Exercising & & & & & & & $<0.05$ \\
\hline Yes & 243 & $76 \cdot 7$ & 104 & $73 \cdot 8$ & 35 & 61.4 & \\
\hline No & 74 & $23 \cdot 3$ & 37 & $26 \cdot 2$ & 22 & 38.6 & \\
\hline Obesity among parents & & & & & & & $<0.01$ \\
\hline Neither & 219 & $69 \cdot 1$ & 81 & $57 \cdot 5$ & 27 & $47 \cdot 3$ & \\
\hline Father & 26 & 8.2 & 15 & $10 \cdot 6$ & 12 & $21 \cdot 1$ & \\
\hline Mother & 50 & $15 \cdot 8$ & 35 & $24 \cdot 8$ & 14 & $24 \cdot 6$ & \\
\hline Both & 22 & 6.9 & 10 & $7 \cdot 1$ & 4 & $7 \cdot 0$ & \\
\hline Dieting & & & & & & & $<0.001$ \\
\hline Yes & 17 & $5 \cdot 4$ & 32 & $22 \cdot 7$ & 14 & $24 \cdot 6$ & \\
\hline No & 300 & 94.6 & 109 & $77 \cdot 3$ & 43 & $75 \cdot 4$ & \\
\hline Year of study & & & & & & & $<0.01$ \\
\hline First & 112 & 35.4 & 37 & $26 \cdot 3$ & 25 & 43.9 & \\
\hline Second & 87 & $27 \cdot 4$ & 36 & 25.5 & 8 & $14 \cdot 0$ & \\
\hline Third & 83 & $26 \cdot 2$ & 36 & 25.5 & 16 & 28.1 & \\
\hline Fourth & 35 & 11.0 & 32 & $22 \cdot 7$ & 8 & $14 \cdot 0$ & \\
\hline
\end{tabular}


Table 2. Risk factors for overweight (BMI $\left.>25 \mathrm{~kg} / \mathrm{m}^{2}\right)$ and obesity $\left(\mathrm{BMl}>30 \mathrm{~kg} / \mathrm{m}^{2}\right)$ among Kuwaiti college men using logistic regression

(Odds ratio (OR) and $95 \%$ confidence intervals)

\begin{tabular}{|c|c|c|c|c|}
\hline \multirow[b]{2}{*}{ Factor } & \multicolumn{2}{|c|}{ Overweight } & \multicolumn{2}{|c|}{ Obese } \\
\hline & OR & $95 \% \mathrm{Cl}$ & OR & $95 \% \mathrm{Cl}$ \\
\hline \multicolumn{5}{|l|}{ Age (years) } \\
\hline$\leq 18$ (reference) & 1.0 & & 1.0 & \\
\hline 19 & 1.42 & $0.59,3.43$ & 1.46 & $0.43,4.99$ \\
\hline 20 & 1.47 & $0.58,3.68$ & 0.69 & $0.17,2.86$ \\
\hline 21 & $3 \cdot 79^{\star *}$ & $1.46,9.86$ & 3.08 & $0.79,11.88$ \\
\hline 22 & 2.06 & $0.74,5.67$ & 1.15 & $0.25,5.27$ \\
\hline$\geq 23$ & $3.03^{*}$ & $1.08,8.49$ & 1.17 & $0.25,5.32$ \\
\hline \multicolumn{5}{|l|}{ Marital status } \\
\hline Single (reference) & 1.0 & & 1.0 & \\
\hline Married & $2 \cdot 31^{*}$ & $1.20,4.48$ & 1.02 & $0.37,2.85$ \\
\hline \multicolumn{5}{|l|}{ Last dental check-up } \\
\hline Don't recall (reference) & 1.0 & & 1.0 & \\
\hline$\geq 2$ years ago & 1.03 & $0.51,2.07$ & 0.62 & $0 \cdot 19,2 \cdot 00$ \\
\hline A year ago & $0.39^{\star *}$ & $0.21,0.72$ & $0.35^{\star}$ & $0.13,0.97$ \\
\hline Last few months & 0.71 & $0.43,1.17$ & 0.49 & $0.21,1 \cdot 13$ \\
\hline \multicolumn{5}{|l|}{ Exercising } \\
\hline Yes (reference) & 1.0 & & $1 \cdot 0$ & \\
\hline No & 1.50 & $0.95,2.34$ & $2.23^{*}$ & $1 \cdot 16,4 \cdot 28$ \\
\hline \multicolumn{5}{|l|}{ Obesity among parents } \\
\hline Neither (reference) & 1.0 & & 1.0 & \\
\hline Father & $2 \cdot 31^{*}$ & $1.21,4.41$ & $3 \cdot 60^{\star *}$ & $1.50,8.62$ \\
\hline Mother & 1.62 & $0.97,2.72$ & 1.88 & $0.86,4 \cdot 11$ \\
\hline Both & 0.91 & $0.41,2.03$ & 1.49 & $0.44,5.04$ \\
\hline \multicolumn{5}{|l|}{ Dieting } \\
\hline Yes (reference) & 1.0 & & $1 \cdot 0$ & \\
\hline No & $0.18^{\star \star \star}$ & $0.09,0.35$ & $0.37^{\star \star *}$ & $0.17,0.81$ \\
\hline \multicolumn{5}{|l|}{ Year of study } \\
\hline First (reference) & 1.0 & & 1.0 & \\
\hline Second & 0.64 & $0.36,1 \cdot 16$ & $1 \cdot 31$ & $0.11,0.82$ \\
\hline Third & 0.71 & $0.37,1.36$ & $0.65^{\star}$ & $0.25,1.60$ \\
\hline Fourth & 1.23 & $0.56,2.67$ & 0.75 & $0.23,2.36$ \\
\hline
\end{tabular}

OR were statistically significant: ${ }^{*} P<0.05,{ }^{* *} P<0.01,{ }^{* \star *} P<0.001$.

(OR 0.39) of overweight than the reference group of those who did not remember having had a dental check-up. Men whose fathers were obese had a significantly $(P<0.05)$ higher risk (OR 2.31) of being overweight in relation to the reference group of men with neither parent being obese. Men who were not dieting had a significantly $(P<0.001)$ lower risk (OR $0 \cdot 18$ ) of being overweight than those who were dieting.

Significant changes in the risk of obesity (BMI $>30 \mathrm{~kg} /$ $\mathrm{m}^{2}$ ) among college men were noted with respect to having had a dental check-up; it was significantly $(P<0 \cdot 05)$ lower (OR 0.35) among those who had had a dental check-up 1 year ago from the time of the study in comparison with the reference group who did not remember having had a dental check-up. Men who were not exercising had a significantly $(P<0.05)$ higher risk (OR 2.23) of obesity than those of the reference population who exercised. Men whose fathers were obese had a significantly $(P<0 \cdot 01)$ higher risk (OR 3.60) of being obese in comparison with the reference men with neither parent being obese. Men who were not dieting at the time of the study had a significantly $(P<0.001)$ lower risk (OR 0.37 ) of being obese than those of the reference population who were dieting. The risk of obesity was significantly $(P<0.05)$ lower $($ OR 0.65$)$ among those in the second year of study in comparison with the reference group in the first year of study.

\section{Discussion}

The present study was based on a limited sample of Kuwaiti college men coming in to register for courses and, therefore, the findings do not necessarily reflect population trends, but reflect the trends among young male college students. This study found that $38.5 \%$ of Kuwaiti college men were considered overweight and $11 \%$ were obese, compared with $8 \%$ and $1 \%$ in European countries; Greece has the heaviest and Scotland the lightest college men (Bellisle et al. 1995). It seems that obesity increases with proximity to the Middle East. Although the rates reported in the present study are much higher than those reported in Europe, they are close to those reported in Arabian Gulf countries; overweight and obesity were found to be 38 and $16 \%$ respectively, in Bahrain (Al-Mannai et al. 1996) and obesity was $15 \%$ in Saudi Arabia (Al-Shoshan, 1990). Moreover, we found that age was significantly associated with overweight and obesity, as have others (Mancini et al. 1986; Young \& Sevenhuysen, 1989; Musaiger et al. 1993). Marital status was significantly associated with overweight and obesity, in agreement with another study (Al-Mannai et al. 1996). Family history of obesity was found to be significantly associated with overweight and obesity, confirming the findings of other earlier studies (Musaiger et al. 1993; 
Amine \& Samy, 1996). It was noted that having had a dental check-up was significantly associated with overweight and obesity. This could not be confirmed by a previous study. Nonetheless, those who had had a dental check-up 1 year ago had about $60 \%$ less risk of being overweight than those who did not recall having had one. Dental check-up was used as a proxy for preventive dental measures or as an example of health awareness; it was assumed that people who pay closer attention to their health are more likely to pay closer attention to their weight, to try to stay fit and to keep weight in line. Physical exercise was significantly associated (negatively) with overweight and obesity, confirming earlier observations on a similar population (Amine \& Samy, 1996). Dieting was significantly associated (positively) with overweight and obesity but in an earlier study such an association was not found (Bellisle et al. 1995). Men who were not dieting at the time of the study had a significantly lower risk (about $80 \%$ ) of being overweight than those who were dieting; for obesity the risk was about $60 \%$ lower. Conversely the risk of overweight among those who dieted increased by about 5 -fold; for obesity, the risk was 2.5 times higher. This is understandable, as it is unlikely that someone would diet if he was not suffering from excess weight or did not want to lose weight.

Theoretically, college men, being highly educated and potentially of higher socio-economic status, are often exposed to, and are heavy consumers of, some forms of the mass media which may provide health-promoting messages put forward by health agencies. Their level of education should enable them to grasp these messages better than those in society who are less well educated (Patterson et al. 1995). The results of the present study (38.5\% overweight and $11.1 \%$ obese) indicate, however, that their ability to translate these health messages into health-promoting behaviours is somewhat questionable.

The rates of overweight and obesity in the present and other Arabian Gulf studies are much higher than those reported in Europe (Bellisle et al. 1995). These differences may be attributed to many factors and to the differences in the model of acceptable physique between the two regions, being more extreme in Europe than in this region, even though food supply is abundant in both. There may be a greater social pressure in Europe to be thin, perhaps, than in this region. It was found that people in the Kuwait region tend to tolerate fatness and that there are no social sanctions against adiposity (Al-Isa, 1989). Decreased physical activity may be foremost among those factors contributing to the level of obesity among Kuwaiti college men. Social and religious norms may preclude some men from engaging in public sports. They may also find engaging in sports at home incongruent with their domestic responsibilities or status. There are also many social occasions like weddings, parties, and religious occasions in which men gather and consume plenty of food; it is usually against Arab customs to refuse partaking of food offered. There may be another factor for the differences in the level of overweight and obesity between Kuwaiti and European college men: plumpness has been considered by some Arabs to be a sign of health and wealth and appearing slim or skinny may be construed by the men as reflecting lower fiscal and social status (Al-Isa, 1989). Further, these differences in the level of overweight and obesity may be attributable to eating in a group $v$. eating alone or in couples, as in Europe. In most cases, Kuwaiti college men eat in large groups which may encourage overeating; Kuwaiti men tend sometimes to compete among each other in the amount of food they can eat. Moreover, the majority of Kuwaiti college men live at home and eat with their families in groups, often served by domestic help; cooking, cleaning and washing clothes are not among their daily chores as perhaps among college students in Europe. Further, it is possible that parents of Kuwaiti college men, having been reared in the leaner years following the initial effects of the changes in the standards of living in the 1950s, may prefer to see their children enjoy, usually at night, the foods they have not had the chance to enjoy, usually eaten at the increasing number, especially after liberation, of fast-food restaurants. An anecdote has been circulating recently which suggests that Kuwait was liberated from the Iraqis and was invaded instead by fastfood restaurants. Moreover, men in this region are more accustomed to social gathering in the 'diwaniyah', the male social-gathering place, unique to Kuwait, where often food is served in abundance, competitively with other diwaniyahs, to the guests by the owner of the diwaniyah. Men in the diwaniyah often compete among themselves in the amount of food they eat. There are over 2200 diwaniyahs in Kuwait frequented at all times, but mostly in the evenings, by men of all ages (Al-Isa, 1997).

Comorbidities which are strongly associated with obesity (Rippe et al. 1998) include type 2 diabetes, CHD, hypertension and dyslipidaemia. These are all common risk factors in Kuwait (Ministry of Public Health, 1996). This is understandable since overweight among Kuwaiti men of all ages is $67.5 \%$ and obesity is $32.3 \%$. Overweight among women is $72.9 \%$ and obesity is $40.6 \%$. These rates are higher than in any other country in which similar studies have been conducted (Al-Isa, 1995, 1997). This may be related to the fact that Kuwaitis in general lead a sedentary lifestyle and overeat, in a stark departure from their lean sea-faring days, before the 1950s, when men worked mostly as sailors and/or divers (for pearls) and women tended house while the men were away at sea most of the year. Today, most Kuwaiti parents are poor role-models for their offspring. This may play a role in the high level of overweight and obesity among Kuwaiti college men.

Although heredity is an important factor in the development of obesity (Stunkard et al. 1986), as was shown in a limited way in this study by the link between paternal obesity and obesity in Kuwaiti college men, sociodemographic, dietary and cultural factors also play a role. Cultural differences and social pressures for slimness may require studies which would compare concern for leanness across various cultures, using the same methodology. Interventions aimed at controlling the syndromes of obesity should have a multisectorial approach. The stark differences between Kuwaiti and European college men should be used to develop messages to raise awareness and develop greater intolerance of the dangers of adiposity among men in this region. These messages should be extensive, beamed through the mass media, especially television, and should project that fatness is a risk factor for a variety of health problems. 


\section{References}

Al-Isa AN (1989) Obesity among Kuwaiti women: an explorative study. PhD Thesis, Manchester Medical School.

Al-Isa AN (1995) Prevalence of obesity among Kuwaitis: a crosssectional study. International Journal of Obesity 19, 431-433.

Al-Isa AN (1997) Temporal changes in BMI and obesity among Kuwaiti men. Annals of Nutrition and Metabolism 41, 307314.

Al-Mannai A, Dickerson JWT, Morgan JB \& Khalfan H (1996) Obesity in Bahraini adults. Journal of the Royal Society of Health 116, 30-32 and 37-40.

Al-Shoshan AA (1990) Some sociodemographic factors influencing the nutritional awareness of the Saudi teens and adults: preliminary observations. Journal of the Royal Society of Health 110, 213-216.

Amine EK \& Samy M (1996) Obesity among female university students in the United Arab Emirates. Journal of the Royal Society of Health 116, 91-96.

Anonymous (1997) Youth risk behaviour surveillance: National College Health Risk Behaviour Survey - United States, 1995. Morbidity and Mortality Weekly Report-CDC Surveillance Summaries 46, 1-56.

Bellisle F, Monneuse MO, Steptoe A \& Wardle J (1995) Weight concerns and eating patterns: a survey of university students in Europe. International Journal of Obesity 19, 723-730.

Haberman S \& Luffey D (1998) Weighing in college students' diet and exercise behaviours. Journal of the American College of Health 46, 189-191.

Kamel BS \& Martinez OB (1984) Food habits and nutrient intake of Kuwaiti males and females. Ecology of Food and Nutrition 15, 261-272.

Makrides L, Veinot P, Richard J, Mckee E \& Gallivan T (1998) A cardiovascular health needs assessment of university students living in residence. Canadian Journal of Public Health 89, 171175.

Mancini M, Contaldo F, Farinaro E, Di Biase G \& Strazzullo P (1986) Medical complications and prevalence of obesity in Italy. Bibliotheca Nutritio Dietetica 37, 1-10.
Matter AM, ALekri SA, Mahdi AR \& Musaiger AO (1990) Growth patterns of adolescents in Bahrain. Journal of the Royal Society of Health 110, 179-180.

Ministry of Public Health (1996) Health and Vital Statistics. Kuwait City, Kuwait: Ministry of Public Health of Kuwait.

Musaiger AO (1990) Nutritional disorders associated with affluence in Bahrain. Family Practice 7, 9-13.

Musaiger AO \& Al-Ansari M (1991-1992) Factors associated with obesity among women in Bahrain. International Quarterly of Community Health Education 12, 129-136.

Musaiger AO, Matter AM, ALekri SA \& Mahdi AR (1993) Obesity among secondary school students in Bahrain. Nutrition and Health 9, 25-32.

Musaiger AO \& Radwan HM (1995) Social and dietary factors associated with obesity in university female students in United Arab Emirates. Journal of the Royal Society of Health 115, 9699.

Patterson RE, Kristal AR, Lynch JC \& White E (1995) Dietcancer related beliefs, knowledge, norms and their relationship to healthful diets. Journal of Nutrition Education 27, 86-92.

Rippe JM, Crossley S \& Ringer R (1998) Obesity as a chronic disease: modern medical and lifestyle management. Journal of the American Dietetic Association 98, S9-S15.

Sciacca JP, Melby CI, Hyner GC, Brown AC \& Femea PI (1991) Body mass index and perceived weight status in young adults. Journal of Community Health 16, 159-168.

Smith BL, Handley P \& Eldredge DA (1998) Sex differences in exercise motivation and body-image satisfaction among college students. Perceptual and Motor Skills 86, 723-732.

Stunkard AJ, Sorensen TI, Hanis C, Teasdale TW, Chakraborty R, Schull WJ \& Schulsinger F (1986) An adoption study of human obesity. New England Journal of Medicine 314, 193-198.

World Health Organization (1990) Diet, Nutrition and the Prevention of Chronic Diseases: Report of WHO Study Group. WHO Technical Report Series no. 797. Geneva: WHO.

Young TK \& Sevenhuysen G (1989) Obesity in Northern Canadian Indians: patterns, determinants, and consequences. American Journal of Clinical Nutrition 49, 786-793. 